\title{
Influence of Activators and Inhibitors on the Collagenase with Collagen Interaction Monitored by Dynamic Light Scattering in Solutions
}

\author{
Irina A. Sergeeva, Anna V. Petrova*, Anastasia V. Shlenskaya, and Galina P. Petrova \\ Chair of Molecular Processes and Extreme Matter States, Faculty of Physics, Lomonosov Moscow State University, \\ GSP-1, 1-2 Leninskie Gory, Moscow 119991, Russian Federation \\ * e-mail: av.sukneva@physics.msu.ru
}

\begin{abstract}
Real-time digestion of type I collagen molecules by bacterial collagenase from Clostridium histolyticum has been monitored using Dynamic Light Scattering method. Time dependencies for translation diffusion coefficient $\left(D_{t}\right)$ and hydrodynamic radius $\left(R_{H}\right)$ on were obtained for pure "collagen + collagenase" Tris-HCl buffer solution at different temperatures and for solutions with added $\mathrm{CaCl}_{2}, \mathrm{ZnCl}_{2}$ and $\mathrm{MgCl}_{2}$ and EDTA. It was shown that digestion of type I collagen molecules by bacterial collagenase is the firstorder reaction. Reaction rate coefficients were calculated. (C) 2021 Journal of Biomedical Photonics \& Engineering.
\end{abstract}

Keywords: dynamic light scattering; type I collagen; translation diffusion coefficient; collagenase from Clostridium histolyticum; first-order reaction; activators; inhibitors; reaction rate coefficient.

Paper \#3405 received 29 Jan 2021; revised manuscript received 1 May 2021; accepted for publication 13 May 2021; published online 2 Jun 2021. doi: 10.18287/JBPE21.07.020305.

\section{Introduction}

Enzyme-based drugs are commonly used in different fields of modern medicine: in surgery, gynecology, otolaryngology, ophthalmology, as well as in dermatology and cosmetology. Bacterial collagenase (for example, from Clostridium histolyticum) is one of them. The main collagenase feature is its ability to digest key protein of the animal extracellular matrix - collagen [1].

Violation of the collagen catabolism leads to fibrosis of organs and tissues. Increasing of collagen degradation rate occurs in case of autoimmune diseases (rheumatoid arthritis, lupus, etc.) because of excess collagenase synthesis as a result of immune response [2].

Clostridium histolyticum collagenases $\mathrm{G}$ and $\mathrm{H}$ (ColG and $\mathrm{ColH}$ ) can easily digest collagens, regardless of their types and sizes [3]. It breaks down multiple bonds in collagen triple helixes as well as peptide bonds [4].

Bacterial collagenase from Clostridium histolyticum is extensively used as a clinical tool in the nonsurgical treatment of Dupuytren's disease $[4,5]$ in eye's diseases treatment, for enzymatic debridement, for accelerated resorption of catgut sutures.

Structural changes of collagen fibrils caused by collagenase are well studied by microscopy, and the degradation rate of protein is determined $[6,7]$. Results obtained with microscopy clearly demonstrate the process of collagen fibers digestion and allow one to evaluate the rate of collagen fibril diameter changing. However, these results do not agree well with the results obtained in conditions close to physiological [6, 7].

Optical methods, like Dynamic Light Scattering (DLS), enable us to investigate collagen and collagenase molecules solutions in conditions close to physiological. By changing the solution's parameters ( $\mathrm{pH}$, temperature, solvent type) and adding of collagenase activators and inhibitors we can simulate the processes in living organisms. In our work, we studied the influence of temperature, activators $\left(\mathrm{CaCl}_{2}\right.$ and $\left.\mathrm{ZnCl}_{2}\right)$ and inhibitors $\left(\mathrm{MgCl}_{2}\right.$ and EDTA) on collagenase activity. Since collagen by collagenase digestion in solutions takes on average $60 \mathrm{~min}$, DLS enables us to monitor the dynamics of this process in real time [8].

\section{Materials}

\subsection{Collagen}

Collagen is the key component of extracellular matrix, making up from $25 \%$ to $35 \%$ of the whole-body protein 
content. Although different types of collagen exist, they all are composed of molecules containing three polypeptide chains arranged in a triple helical conformation [6].

Over $90 \%$ of the collagen in the human body is type I collagen. It is a component of skin, bone, tendon and other fibrous connective tissues [9]. Molecular mass of collagen is approximately $300 \mathrm{kDa}$, average length of molecule is $300 \mathrm{~nm}$ [10].

In normal healthy tissues collagen molecules are resistant to most proteases attacks. Only specialized enzymes like collagenases can attack the collagen molecule.

\subsection{Collagenase}

There are two types of collagenase: tissue and bacterial. Tissue collagenases split collagen in its native triple helical conformation at a specific site, yielding fragments representing $3 / 4$ and $1 / 4$ lengths of the collagen molecule. After fragmentation the pieces tend to uncoil into random polypeptides and are more susceptible to attack by other protease [11].

Bacterial collagenases attack many sites along the helix. Collagenases from Clostridium histolyticum degrades the helical regions in native collagen preferentially at the X-Gly bond in the sequence Pro-X-Gly-Pro where $\mathrm{X}$ is most frequently a neutral amino acid [12]. This bond in synthetic peptide substrates may also be split. Bacterial collagenase cleaves the peptide bond of collagen in more than 200 places [11].

Molecular mass of collagenase is $79 \mathrm{kDa}$. Hydrodynamic radius is $4 \mathrm{~nm}$ according to the data obtained by dynamic light scattering method [5].

\subsection{Enzymes activators and inhibitors}

Enzyme activators are molecules or ions that bind to enzymes and increase their activity. Collagenases from Clostridium histolyticum are activated by ions $\mathrm{Ca}^{2+}$, $\mathrm{Zn}^{2+}[13,14]$. Calcium ions support the conformation of the enzyme which is required for binding to the protein peptide chain. This conformation makes the active site available for the reaction. $\mathrm{Zn}^{2+}$ ions also are activators of collagenase, but its effect on the enzyme activity is much lower than that of $\mathrm{Ca}^{2+} . \mathrm{Zn}^{2+}$ ions are located in the active site of the enzyme. Enzyme inhibitors are molecules that binds to an enzyme and decreases its activity. Collagenases from Clostridium histolyticum are inhibited by ions $\mathrm{Mg}^{2+}$, EDTA, 1,10-phenanthroline, dipyridyl disulfide, 8-hydroxyquinoline $[15,16]$.

\section{Experimental method}

\subsection{Dynamic Light Scattering}

The DLS method enables one to determine the translation diffusion coefficient of particles in solutions by analyzing characteristic time of scattered light intensity fluctuations [17].
Translation diffusion coefficient of the particles is proportional to the decay rate of light scattering intensity fluctuations. The decay rate is obtained from the timedependent correlation function of the scattered light intensity.

In the case of poly-dispersed solution where the particle sizes are different, the spectrum of the photocurrent is a continuous set (integral) of Lorentz curves with different half-widths. Consequently, to find the size distribution of particles (diffusion coefficients), it is necessary to solve the inverse spectral problem in the form of an integral equation with a Lorentzian kernel:

$$
\begin{aligned}
& g^{(2)}(t)=\left[g^{(1)}(t)\right]^{2}+1+\zeta(t), \\
& g^{(1)}(t)=\int_{0}^{\infty} P(\Gamma) e^{-\Gamma t} \partial \Gamma
\end{aligned}
$$

where $g^{(1)}(t)$ - is the normalized autocorrelation function of the signal, $\zeta(t)$ - is the error associated with the stochastic nature of the signal itself [17]. If we neglect the influence of constant experimental noise $\zeta(t)$, Eq. (1) (Siegert relation) will allow us to calculate $g^{(1)}(t)$ in terms of $g^{(2)}(t)$, accumulated by the correlator during the experiment.

Integral Eq. (2) forms the basic principle of data processing in the photon correlation spectroscopy technique. This equation for $\mathrm{P}(\Gamma)$ is a Fredholm integral first-order equation, known in mathematics as an ill-posed problem, that is a problem with a fundamentally absent algorithm for finding an exact solution. In this regard, various approximate solution methods are being developed, many of which give very good results.

In the experiments, the results were processed using the DYNALS software, in which the search for an approximate solution (4) is carried out using the regularization method of $\mathrm{A}$. N. Tikhonov for integral equations [18].

$\Gamma$ can calculated as described below:

$$
\begin{aligned}
& \Gamma=D_{t} q^{2}, \\
& q=\frac{4 \pi n}{\lambda} \sin \frac{\theta}{2}, \\
& D_{t}=\frac{k T}{6 \pi \eta R_{H}},
\end{aligned}
$$

where $D_{t}$ is the translation diffusion coefficient, $q$ is the scattering vector, $n$ is the refraction index, $\lambda$ is the scattered light wave length, $\theta$ is the scattering angle, $k$ is the Boltzmann constant, $\eta$ is the dynamic viscosity of the solvent, $T$ is the absolute temperature of the solution and $R_{H}$ is the hydrodynamic radius.

\subsection{Samples preparation}

Collagen solutions were prepared by dissolving collagen type I from calf skin produced by Sigma Aldrich in $10 \mathrm{mM}$ Tris- $\mathrm{HCl}$ (pH 7.5) buffer. Bacterial collagenase 
from Clostridium histolyticum type IA by Sigma Aldrich was added in collagen solution. Concentration of collagen was $0.1 \mathrm{mg} / \mathrm{ml}$, concentration of collagenase was $0.2 \mathrm{mg} / \mathrm{ml}$ (i.e 8 molecules of collagenase per 1 molecule of collagen).

As activators we have used salts $\mathrm{CaCl}_{2}, \mathrm{ZnCl}_{2}$ and as inhibitors - salt $\mathrm{MgCl}_{2}$ and EDTA. Ionic strengths were $0.03 \mathrm{~mol} / \mathrm{L}$ in all solutions.

The samples were processed in the ultrasonic bath with the frequency $3 \mathrm{kHz}$ during $1 \mathrm{~min}$.

Experiments have been carried out using the photoncorrelation spectrometer Photocor-Complex with diode laser (wavelength of $647 \mathrm{~nm}$, power $25 \mathrm{~mW}$ ) [19]. Photocor-Complex spectrometer is equipped with builtin thermostat which allows one to control sample temperature.

\section{Results and Discussions}

\subsection{Temperature dependencies}

Using the DLS method we have experimentally obtained translation diffusion coefficient $\left(D_{t}\right)$ on time dependencies of scattering particles in "collagen + collagenase" Tris- $\mathrm{HCl}$ buffer solution at different temperatures (Fig. 1).

The uniform increase in the mobility of scattering particles over time was observed at $22{ }^{\circ} \mathrm{C}$ and $30^{\circ} \mathrm{C}$. The maximum growth of $D_{t}$ (and speed) is observed during the first $30 \mathrm{~min}$, then the increase is not so rapid. At $40{ }^{\circ} \mathrm{C}$ average mobility of scattered particles is increasing threefold during first $30 \mathrm{~min}$ and then $D_{t}$ on time dependence reaches saturation.

Since $T=40^{\circ} \mathrm{C}$ is not optimal for collagen (protein can denature), all further experiments were carried out at $T=30{ }^{\circ} \mathrm{C}$ (as the most optimal temperature).

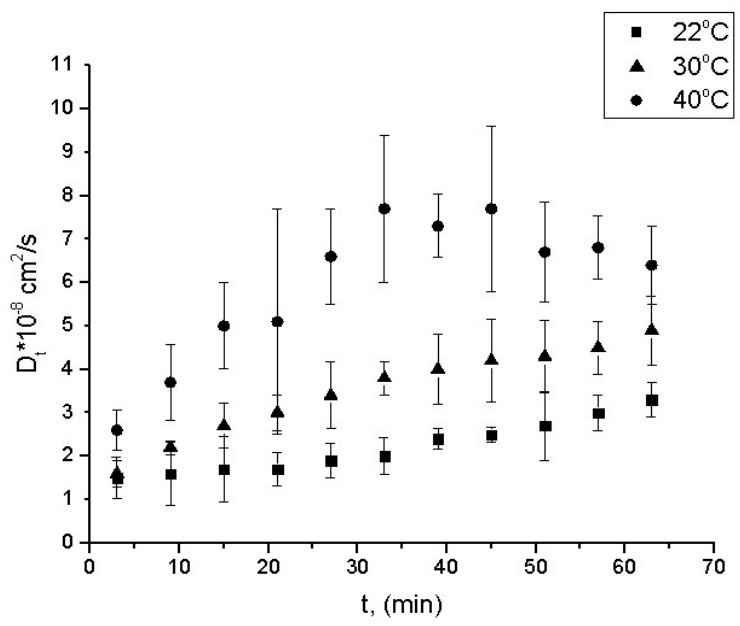

Fig. 1 Time dependencies of translation diffusion coefficient $\left(D_{t}\right)$ on of scattering particles in "collagen + collagenase" Tris- $\mathrm{HCl}$ buffer solution at different temperatures.

Using the DYNALS package of programs evaluated values of hydrodynamic radius $R_{H}$ has been calculated from $D_{t}$ and then $\ln R_{H}(t)$ dependencies were obtained (Fig. 2).

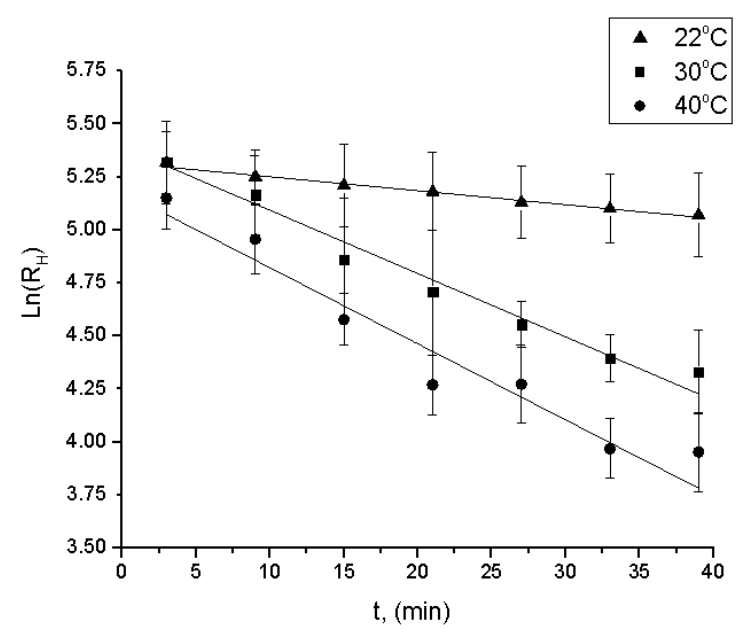

Fig. 2 The $\ln R_{H}$ dependencies on time at different temperatures, where $R_{H}$ is hydrodynamic radius of scattering particles in "collagen + collagenase" Tris- $\mathrm{HCl}$ buffer solution.

In the first approximation, we can assume that concentration of collagen molecules in solution linearly depends on radius. In this case concentration of collagen molecules $(C)$ exponentially decreases with time. Such character of $C(t)$ dependence corresponds to the firstorder reaction [20].

The equations describing first-order reaction kinetics are given below. $C_{0}$ is initial concentration, $k_{1}$ is the reaction rate coefficient in units $1 /$ time.

$$
\begin{aligned}
& \ln C=\ln C_{0}-k_{1} \tau, \\
& k_{1}=-\tan \alpha .
\end{aligned}
$$

Plotting $\ln (C)$ with respect to time for a first-order gives us a straight line with the slope of the line equal to $-\mathrm{k}_{1}$ (Fig. 2).

In the Table 1 values of $k_{1}\left(\mathrm{~min}^{-1}\right)$ for different temperatures are presented. STD $k_{1}$ was calculated using a graphing program based on the least squares method.

Table 1 Values of $k_{1}\left(\mathrm{~min}^{-1}\right)$.

\begin{tabular}{ccc} 
Temperature, ${ }^{\circ} \mathrm{C}$ & $k_{1}$ & STD $k_{1}$ \\
\hline 22 & 0.012 & 0.001 \\
\hline 30 & 0.031 & 0.003 \\
\hline 40 & 0.054 & 0.003
\end{tabular}

The highest value of $k_{1}$ corresponds to $40{ }^{\circ} \mathrm{C}$. However, this temperature is not optimal for collagen. With prolonged thermal action protein may denaturate, which happened at $90^{\text {th }}$ min of the experiment. 


\section{2 "Collagen + collagenase" solutions with activators $\mathrm{CaCl}_{2}$ and $\mathrm{ZnCl}_{2}$}

We have selected the following scheme for investigations of "collagen + collagenase" solutions with activators and inhibitors: experimentally obtain translation diffusion coefficient on time $D_{t}(t)$ dependence, evaluate values of hydrodynamic radius $R_{H}$ from $D_{t}$, plot $\ln R_{H}(t)$ dependencies.

The $\ln R_{H}(t)$ dependencies for pure "collagen + collagenase" Tris- $\mathrm{HCl}$ buffer solution and in solutions with added $\mathrm{CaCl}_{2}$ and $\mathrm{ZnCl}_{2}$ are presented in Fig. 3 . Calculated values of $k_{1}\left(\mathrm{~min}^{-1}\right)$ are presented in Table 2 .



Fig. 3 The $\ln R_{H}$ time dependencies, where $R_{H}$ is hydrodynamic radius of scattering particles, in pure "collagen + collagenase" Tris- $\mathrm{HCl}$ buffer solution (1) and with added $\mathrm{ZnCl}_{2}$ (2) and $\mathrm{CaCl}_{2}(3), T=30{ }^{\circ} \mathrm{C}$.

Bacterial collagenase initially contains $\mathrm{Zn}^{2+}$ and $\mathrm{Ca}^{2+}$ ions. $\mathrm{Zn}^{2+}$ is responsible for the activation of amide group and $\mathrm{Ca}^{2+}$ for the formation of tertiary structure [21].

When $\mathrm{ZnCl}_{2}$ is added to "collagen + collagenase" Tris- $\mathrm{HCl}$ buffer solution, $\mathrm{Zn}^{2+}$ ions may occupy calcium positions in collagenase, but due to the difference in ionic radii $\left(r_{\text {ion }}\left(\mathrm{Ca}^{2+}\right)=114 \mathrm{pm}, r_{\text {ion }}\left(\mathrm{Zn}^{2+}\right)=88 \mathrm{pm}\right)$ the effect of activity centers formation is not fully achieved (Fig. 3, curve 2).

When $\mathrm{CaCl}_{2}$ is added to "collagen + collagenase" Tris- $\mathrm{HCl}$ buffer solution $\mathrm{Ca}^{2+}$ ions occupy all available positions in collagenase and form maximum number of active centers (Fig. 3, curve 3).

Also, for the solution with $\mathrm{CaCl}_{2}$ added $\ln R_{H}(t)$ dependence becomes non-linear after $20 \mathrm{~min}$ (Fig. 3, curve 3 ). We suppose that it corresponds to further digestion of collagen molecule's pieces by bacterial collagenase. Unlike tissue collagenase which splits collagen in its native triple-helical conformation at a specific site, bacterial collagenase is able also to attack and degrade collagen molecule's fragments [11].

\section{3 "Collagen + collagenase" solutions with inhibitor EDTA}

To investigate inhibitor influence on collagen by collagenase digestion, we have added EDTA to "collagen + collagenase" Tris-HCl buffer solution. During first $30 \mathrm{~min} D_{t}$ value was changed from $(1.5 \pm 0.2) \times 10^{-8} \mathrm{~cm}^{2} / \mathrm{s}$ to $(2.1 \pm 0.3) \times 10^{-8} \mathrm{~cm}^{2} / \mathrm{s}$, and during next $30 \mathrm{~min}$ from $(2.1 \pm 0.3) \times 10^{-8} \mathrm{~cm}^{2} / \mathrm{s}$ to $(2.6 \pm 0.4) \times 10^{-8} \mathrm{~cm}^{2} / \mathrm{s}$.

At $64^{\text {th }}$ minute $\mathrm{CaCl}_{2}$ as an activator was added to "collagen + collagenase + EDTA" solution. In half an hour after that $D_{t}$ value changed from $(2.6 \pm 0.4) \times 10^{-8}$ $\mathrm{cm}^{2} / \mathrm{s}$ to $(10.0 \pm 1.2) \times 10^{-8} \mathrm{~cm}^{2} / \mathrm{s}$, and in $1 \mathrm{~h}$ to $(13.0 \pm 2.1) \times 10^{-8} \mathrm{~cm}^{2} / \mathrm{s}$ (Fig. 4$)$



Fig. 4 Translation diffusion coefficient $\left(D_{t}\right)$ on time dependencies of scattering particles in "collagen + collagenase" Tris- $\mathrm{HCl}$ buffer solution with added EDTA (1) and EDTA with $\mathrm{CaCl}_{2}$ (2), $T=30^{\circ} \mathrm{C}$.

Corresponding hydrodynamic radius $R_{H}$ values were calculated and $\ln R_{H}(t)$ dependencies were obtained for pure "collagen + collagenase" Tris- $\mathrm{HCl}$ buffer solution and for solutions with added EDTA and EDTA $+\mathrm{CaCl}_{2}$ (Fig. 5). Values of $k_{1}\left(\mathrm{~min}^{-1}\right)$ are presented in Table 2.

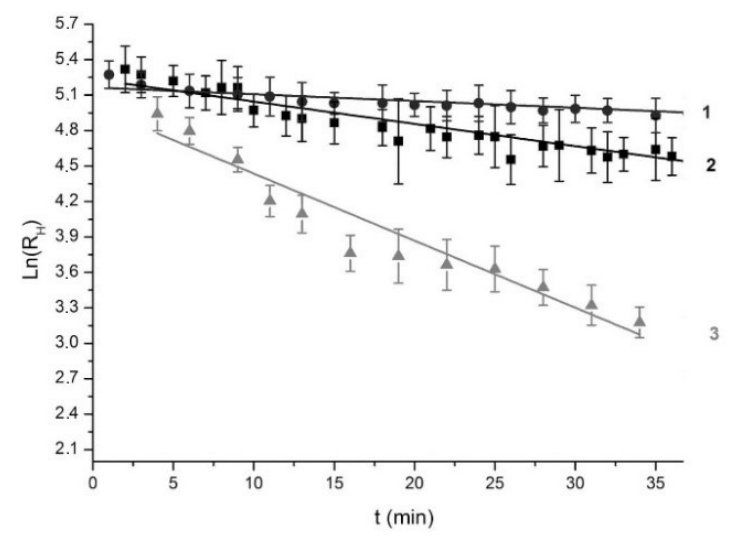

Fig. 5 The $\ln R_{h}$ time dependencies, where $R_{h}$ is hydrodynamic radius of scattering particles, in pure "collagen + collagenase" Tris- $\mathrm{HCl}$ buffer solution (2) and with added EDTA (1) and EDTA with $\mathrm{CaCl}_{2}(3), T=30^{\circ} \mathrm{C}$.

EDTA molecules bind with calcium ions in solution and block calcium ions access to all available places in collagenase. So collagen by collagenase digestion slows down (Figs. 5, 6). When we add $\mathrm{CaCl}_{2}$ to 
"collagen + collagenase + EDTA" solution, amount of $\mathrm{Ca}^{2+}$ ions recovers and collagenase activity restores.

\section{4 "Collagen + collagenase" solutions with inhibitor $\mathrm{MgCl}_{2}$}

The same way we have investigated $\mathrm{MgCl}_{2}$ influence on collagen by collagenase digestion. $D_{t}(t)$ and $\ln R_{H}(t)$ dependencies were obtained (Figs. 6, 7).

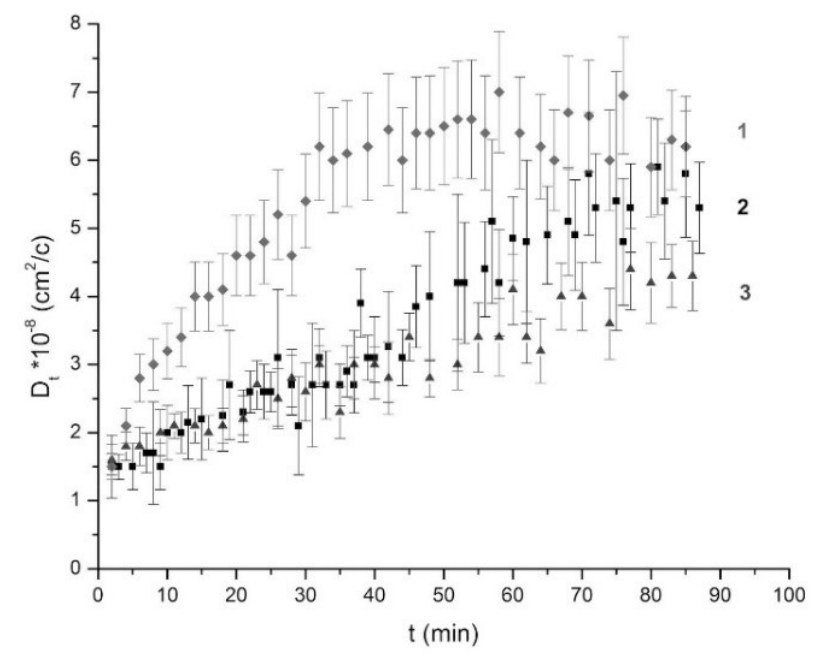

Fig. 6 The time dependencies of translation diffusion coefficient $\left(D_{t}\right)$ of scattering particles in "collagen + collagenase" Tris- $\mathrm{HCl}$ buffer solution (2) with added $\mathrm{MgCl}_{2}$ (3) and with added $\mathrm{MgCl}_{2}$ and $\mathrm{CaCl}_{2}$ (1), $T=30^{\circ} \mathrm{C}$.

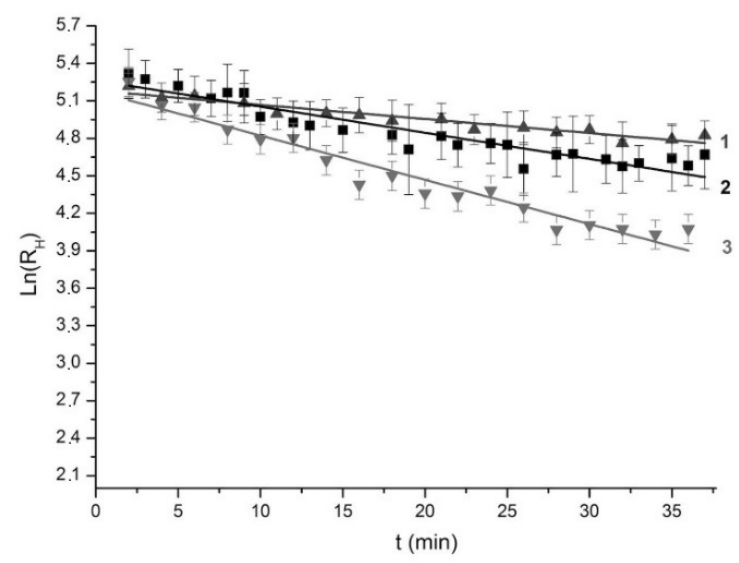

Fig. 7 The $\ln R_{h}$ time dependencies, where $R_{h}$ is hydrodynamic radius of scattering particles, in pure "collagen + collagenase" Tris- $\mathrm{HCl}$ buffer solution (2) added $\mathrm{MgCl}_{2}$ (1) and $\mathrm{MgCl}_{2}$ with $\mathrm{CaCl}_{2}(3), T=30{ }^{\circ} \mathrm{C}$.

According to the Pearson acid base concept $\mathrm{Ca}^{2+}$ and $\mathrm{Mg}^{2+}$ are hard Lewis acids and $\mathrm{Zn}^{2+}$ is intermediate Lewis acid [22].

When $\mathrm{MgCl}_{2}$ is added to "collagen + collagenase" Tris- $\mathrm{HCl}$ buffer solution magnesium mainly aims to replace the zinc in collagenase due to close values of the ionic radii: $r_{\text {ion }}\left(\mathrm{Mg}^{2+}\right)=6 \mathrm{pm}, \quad r_{\text {ion }}\left(\mathrm{Zn}^{2+}\right)=88 \mathrm{pm}$.
However, $\mathrm{Mg}^{2+}$ is hard Lewis acid and it decreases the activity of the amide group in enzyme. This fact leads to the inhibition of protein destruction process (Fig. 3, 5). Calculated values of $k_{1}\left(\mathrm{~min}^{-1}\right)$ are presented in Table 2 .

When we add $\mathrm{CaCl}_{2}$ to "collagen + collagenase + $\mathrm{MgCl}_{2}$ " solution, collagenase activity partially restores but initial value is not achieved.

\section{Conclusions}

Presented results allow one to draw a conclusion that digestion of type I collagen molecules by bacterial collagenase is the first-order reaction. Corresponding values of $k_{1}\left(\mathrm{~min}^{-1}\right)$ calculated for solutions with activators and inhibitors are given in Table 2.

Table 2 Values of $k_{l}\left(\mathrm{~min}^{-1}\right)$

\begin{tabular}{lcc}
\multicolumn{1}{c}{ Solution } & $\boldsymbol{k}_{\mathbf{1}}$ & STD $\boldsymbol{k}_{\mathbf{1}}$ \\
\hline Collagen + Collagenase & 0.023 & 0.002 \\
\hline $\begin{array}{l}\text { Collagen }+ \text { Collagenase }+ \\
\mathrm{ZnCl}_{2}\end{array}$ & 0.051 & 0.004 \\
$\begin{array}{l}\text { Collagen }+ \text { Collagenase }+ \\
\mathrm{CaCl}_{2}\end{array}$ & 0.104 & 0.008 \\
\hline $\begin{array}{l}\text { Collagen }+ \text { Collagenase }+ \\
\mathrm{MgCl}_{2}\end{array}$ & 0.011 & 0.001 \\
\hline $\begin{array}{l}\text { Collagen }+ \text { Collagenase }+ \\
\text { EDTA }\end{array}$ & 0.006 & 0.001 \\
$\begin{array}{l}\text { Collagen }+\mathrm{Collagenase}^{+} \\
\mathrm{MgCl}_{2}+\mathrm{CaCl}_{2}\end{array}$ & 0.035 & 0.003 \\
$\begin{array}{l}\text { Collagen }+\mathrm{Collagenase}^{+} \\
\text {EDTA }+\mathrm{CaCl}_{2}\end{array}$ & 0.057 & 0.004
\end{tabular}

It was found that the most efficient activator of collagen type I digestion by collagenase is $\mathrm{Ca}^{2+}$ and the most efficient inhibitor is EDTA.

It was shown that influence of EDTA and $\mathrm{MgCl}_{2}$ on collagen type I digestion by collagenase may be reduced by adding $\mathrm{CaCl}_{2}$ to the solution. $\mathrm{Ca}^{2+}$ ions restore collagenase activity.

The obtained results demonstrate that Dynamic Light Scattering method can be used for first-order reaction rate coefficient $\mathrm{k}_{1}$ determination. The key advantage of Dynamic Light Scattering based $k_{1}$ measurement is the possibility of real-time digestion monitoring. By variating temperature, solution formula and collagencollagenase ratio different physiological states can be simulated for in vitro investigation.

\section{Disclosures}

All authors declare that there is no conflict of interests in this paper. 


\section{Acknowledgements}

The authors would like to thank Dr. Nataliya E. Borisova from Department of Radiochemistry, Chemical Faculty, Lomonosov Moscow State University for the opinion of an expert and for providing $\mathrm{ZnCl}_{2}$ and $\mathrm{MgCl}_{2}$.
This research has been supported by the Interdisciplinary Scientific and Educational School of Moscow University «Photonic and Quantum Technologies. Digital Medicine».

\section{References}

1. R. Bauer, K. Janowska, K. Taylor, B. Jordan, S. Gann, T. Janowski, E. C. Latimer, O. Matsushita, and J. Sakon, "Structures of three polycystic kidney disease-like domains from Clostridium histolyticum collagenases ColG and ColH," Acta Crystallographica Section D: Biological Crystallography 71(3), 565-577 (2015).

2. I. Mandl, "Collagenases and elastases," in Advances in Enzymology and Related Areas of Molecular Biology 23, F. F. Nord (Eds.), Interscience Publishers, New York, 163-264 (1961).

3. Collagenase from Clostridium histolyticum, Merck KGaA, (accessed 01 May 2021). [https://www.sigmaaldrich.com/catalog/product/sigma/c9891].

4. S. Müller-Herrmann, T. Scheibel, "Enzymatic degradation of films, particles, and nonwoven meshes made of a recombinant spider silk protein," ACS Biomaterials Science \& Engineering 1(4), 247-259 (2017).

5. J. Nanchahal, K.S. Midwood, "Treatment for dupuytren's disease," Isis Innovation Limited 8(2), 22-23 (2015).

6. M. F. Paige, A. C. Lin, and M. C. Goh, "Real-time enzymatic biodegradation of collagen fibrils monitored by atomic force microscopy," International Biodeterioration \& Biodegradation 50(1), 1-10 (2002).

7. S. K. Mallya, K. A. Mookhtiar, and H. E. Van Wart, "Kinetics of hydrolysis of type I, II, and III collagens by the class I and II Clostridium histolyticum collagenases," Journal of Protein Chemistry 11(1), 99-107 (1992).

8. A. V. Petrova, I. A. Sergeeva, G. P. Petrova, and A. V. Mitrofanova, "The Features of Interaction of Collagen and Collagenase Molecules in the Presence of Chromium and Calcium Ions in Solutions by Dynamic Light Scattering," Moscow University Physics Bulletin 75(6), 611-617 (2020).

9. R. Ritchie, W. Yang, and M. Meyers, "Structural Architectures with Toughening Mechanisms in Nature: A Review of the Materials Science of Type-I Collagenous Materials," Progress in Materials Science 103, 425-483 (2019).

10. K. Wu, W. Liu, and G. Li, "The aggregation behavior of native collagen in dilute solution studied by intrinsic fluorescence and external probing," Spectrochimica Acta Part A: Molecular and Biomolecular Spectroscopy 102, 186-193 (2012).

11. Worthington Tissue Dissociation Guide, Worthington Biochemical Corporation, (accessed 01 May 2021 ). [http://www.worthington-biochem.com/tissuedissociation/collagenase.html].

12. N. Ohbayashi, N. Yamagata, M. Goto, K. Watanabe, Y. Yamagata, and K. Murayama, "Enhancement of the Structural Stability of Full-Length Clostridial Collagenase by Calcium Ions," Applied and Enviromental Microbiology 78, 5839-5844 (2012).

13. J. J. Wilson, O. Matsushita, A. Okabe, and J. Sakon, "A Bacterial Collagen-binding Domain with Novel Calciumbinding Motif Controls Domain Orientation," The EMBO Journal 22(8), 1743-52 (2003).

14. E. L. Angleton, H. E. Van Wart, "Preparation and Reconstitution with Divalent Metal Ions of Class I and Class II Clostridium histolyticum apocollagenases," Biochemistry 27(19), 7406-7412 (1988).

15. S. Seifter, P. M. Gallop, LeRoy Klein, and E. Meilman, "Studies on Collagen: II. Properties of Purified Collagenase and Its Inhibition,” Journal of Biological Chemistry 234(1), 285-293 (1959).

16. P. Seglen, "Preparation of isolated rat liver cells," Methods in Cell Biology 13, 29-83 (1976).

17. H. Z. Cummins, E. R. Paik (Eds.), Photon Correlation and Light Beating Spectroscopy, Springer Science and Business Media, New York (1974). ISBN: 978-1-4615-8906-8.

18. [http://www.softscientific.com/science/WhitePapers/dynals1/dynals100.htm].

19. Multi-angle particle size analyzer Photocor Complex, Photocor Instrument, (accessed 01 May 2021). [http://www.photocor.com/dls-instrument].

20. P. Atkins, J. Paula, Physical Chemistry, 8-th ed., W. H. Freeman and Company, Gordonsville, USA (2006).

21. U. Eckhard, E. Schönauer, D. Nüss, and H. Brandstetter, "Structure of collagenase G reveals a chew-and-digest mechanism of bacterial collagenolysis," Nature Structural \& Molecular Biology 18(10), 1109-1115 (2011).

22. G. P. Robert, R. G. Pearson, “Absolute Hardness: Companion Parameter to Absolute Electronegativity,” Journal of the American Chemical Society 105(26), 7512-7516 (1983). 